\title{
Craniosquise with Meningocelis in Newborn Calf
}

\author{
André Giarola Boscarato', Filipe Correa Pacheco', Carla Faria Orlandini de Andrade'2, \\ Giovanna Fernanda Jardim³, João Antonio Berta de Oliveira ${ }^{3}$, Rita de Cássia Lima Ribeiro', \\ Salviano Tramontin Belettini' \& Luiz Romulo Alberton'
}

\begin{abstract}
Background: Cranioschisis is a malformation that occurs during embryological development and results in incomplete closure of the skull, leaving an opening through which the intracranial tissue can project. Meningocele consists of herniation of the meninges containing cerebrospinal fluid through the cranial defect. In cattle, this association usually manifested by the appearance of a floating saccular protrusion of variable size and volume in the frontal or parietal region of the cranium. This manuscript aims to report a case of cranioschisis associated with meningocele and neurological deficit in a newborn calf in the northwestern region of the state of Paraná.

Case: A 2-day-old crossbred female calf was diagnosed with cranioschisis associated with meningocele in the frontal region of the head. On initial clinical examination, an ovoid mass with floating appearance was observed, extending from the supraorbital curvature of the frontal bone to the end of the nasal bones following the midline. The patient had normal parameters for the species and age and a positive sucking reflex. Neurological examination showed permanent lateral decubitus position, spastic paresis of the thoracic limbs and opisthotonus. Complementary imaging studies, including xrays and ultrasonography, showed a failure in the frontal bone, approximately $5 \mathrm{~cm}$ in diameter. Despite the unfavorable prognosis, surgical reduction was chosen. After drainage of the cerebrospinal fluid, excision of the meningeal sac was continuously performed, exposing the subarachnoid space, showing circular failure in the frontal bone with a diameter of $4.5 \mathrm{~cm}$, making it possible to observe part of the right frontal lobe. We opted for occlusion of the bone defect by covering it with the dura mater. Absorbable 0 catgut suture was applied in a simple continuous pattern for coaptation of the meningeal edges. The technique used proved to be viable, but due to lack of therapeutic response and maintenance of the neurological picture, the animal was euthanized three days after surgery.

Discussion: The clinical signs of meningocele are generally observed in newborn calves, and the pathology is not reported in aborted animals, which explains the fact that all cases reported in the literature are of calves born at term. Treatment success is variable. In general, it depends on the absence of neurological symptoms, which are invariably linked to morphological alterations in nervous tissue. Thus, animals with neurological symptoms have poor prognosis and may even die spontaneously. In some cases surgical reduction without the use of grafts, as in this report, was successfully performed. The authors reported covering a $7-\mathrm{cm}$ circular gap in the frontal bone thought coaptation of the meningeal edges using a simple continuous pattern of nylon suture, followed by dehorning. In this case, the animal showed no neurological abnormalities and had a good prognosis. We conclude that the surgical treatment of cranioschisis associated with meningocele in bovine species presented in this report had an unfavorable prognosis. As observed in other cases, when the animals have neurological symptoms the prognosis is bleak, probably due to morphological and functional changes of congenital origin in the nervous tissue, as described in the literature. More case studies are needed to elucidate the etiology and pathogenesis of this disorder in bovines, since the cases described in the literature are not associated with the most commonly reported causes, such as the ingestion of certain plants.
\end{abstract}

Keywords: cattle, malformation, meninges, nervous system, skull. 


\section{INTRODUCTION}

Congenital deformities are manifested through the morphological and functional impairment of tissues and/or organic systems and may arise during embryonic, development in all species of animals [2], or even after organogenesis in already differentiated structures [10], caused by ingestion of toxic plants with teratogenic potential, viruses, nutritional factors related to micronutrients, and mycotoxins and pesticides, among other causes.

Cranioschisis is a malformation that occurs during embryological development [12] and results in incomplete closure of the skull, leaving an opening through which the intracranial tissue can project [7]. Meningocele consists of herniation of the meninges containing cerebrospinal fluid through the cranial defect [7].

In cattle, meningocele associated with cranioschisis usually is manifested by the appearance of a floating saccular protrusion of variable size and volume in the frontal $[8,11]$ or parietal region [9] of the cranium.

The diagnosis is made by physical examination and using imaging techniques such as radiography, ultrasonography, computed tomography, and magnetic resonance imaging [6], allowing the determination, with great accuracy, of the characteristics of the alteration, aiding therapeutic management. The prognosis with surgical reduction is good in some cases [8].

This manuscript aims to report a case of cranioschisis associated with meningocele and neurological deficit in a newborn calf in the northwestern region of the state of Paraná.

\section{CASE}

A 48-h-old girolando calf weighing $25 \mathrm{~kg}$ was attended by the clinical sector of large animals at the Veterinary Hospital of the Paranaense University (UNIPAR). The person responsible for performing anamnesis reported an increase in volume in the facial region of the animal with onset at the moment of eutocic delivery. He also reported that due to the inability in moving and maintaining quadruped position, colostrum and milk were administered through a bottle, which was well accepted by the calf. On clinical examination, there was an increase in volume in the frontal region of approximately $25 \mathrm{~cm}$ in length, 15 $\mathrm{cm}$ in height, and $15 \mathrm{~cm}$ in width, with a rounded and floating appearance, extending from the supraorbital curvature of the frontal bone to the end of the nasal bones following the midline (Figure 1A).

The vital parameters were within the physiological parameters for the species and age. The calf had a heart rate of $100 \mathrm{bpm}$, respiratory rate of 40/min, rectal temperature of $38.7^{\circ} \mathrm{C}$, normal colored mucous membranes, normal pulse, and it was hydrated. Due to its inability in maintaining in standing position, a specific clinical examination of the nervous system was performed. Permanent lateral decubitus was observed, with the presence of opisthotonus, spastic paresis in the thoracic limbs and flaccid paresis of the pelvic limbs (Figure 1B), tremors and eventual pedal movements, alert attitude, absence of alterations in pairs of cranial nerves, and presence of sucking reflex. In addition to imaging studies including $\mathrm{x}$-rays and ultrasonography, hemograms and biochemical exams were also performed. The hematological and biochemical examination showed values within the physiological parameters for the species. Radiographic examination revealed a mass with radio-opacity characteristic of soft tissue and rounded and well-defined contours, located externally and in close contact with the skull in the frontal bone (Figure 1C). The ultrasonographic image showed hypoechoic content with loss of bone continuity of the frontal cranial bone and communication with the braincase (Figure 1D). During the ultrasonographic examination, after trichotomy and aseptic preparation, an ultrasound-guided puncture was performed, and serosanguineous fluid was recovered, which was identified as cerebrospinal fluid on clinical laboratory analysis. Based on the clinical findings and complementary examinations, a diagnosis of cranioschisis with meningocele was made. Despite the unfavorable prognosis, surgical treatment was chosen. The animal received midazolam $\left(\text { Dormire }^{\circledR}\right)^{1}[0.4 \mathrm{mg} / \mathrm{kg}]$ as pre-anesthetic medication, propofol (Propovan $\left.{ }^{\circledR}\right)^{1}[4 \mathrm{mg} / \mathrm{kg}]$ for induction, and isoflurane (Isoforine $\left.{ }^{\circledR}\right)^{1}$ for anesthetic maintenance. The animal was kept in sternal decubitus position and, after trichotomy and standard surgical preparation, the lesion was punctured with a 40x12 mm needle. One thousand $\mathrm{mL}$ of fluid content with hemorrhagic appearance was recovered, identified as cerebrospinal fluid on laboratory examination. Subsequently, an incision was made with a scalpel in the skin, following the circumference of the meningocele, and the skin covering the meningeal sac was carefully dissected, exposing the dura mater. Excision of the meningeal sac was continuously performed, exposing the subarachnoid space, showing circular 
failure in the frontal bone with a diameter of $4.5 \mathrm{~cm}$, making it possible to observe part of the right frontal lobe (Figure 2A). We opted for occlusion of the bone defect by covering it with the dura mater. Absorbable 0 catgut suture was applied in a simple continuous pattern for coaptation of the meningeal edges (Figure 2B). The subcutaneous tissue was approached again with the same continuous suture in a mattress pattern, and the skin was reapproximated with 1 nylon thread. In the postoperative period, antibiotic therapy with ceftiofur $\left(\mathrm{TopCef}^{\circledR}\right)^{2}[2.2$ $\mathrm{mg} / \mathrm{kg}$, flunixin meglumine (Flunexim Injetável $\left.{ }^{\circledR}\right)^{3}[1.1$ $\mathrm{mg} / \mathrm{kg}]$, dexamethasone $\left(\mathrm{CortVet}^{\circledR}\right)^{4}[0.5 \mathrm{mg} / \mathrm{kg}]$, furosemide $\left(\text { Zalix }^{\circledR}\right)^{5}[2 \mathrm{mg} / \mathrm{kg}]$, and mannitol $\left(\text { Manitol }^{\circledR}\right)^{6}$ was established. The neurological picture showed no

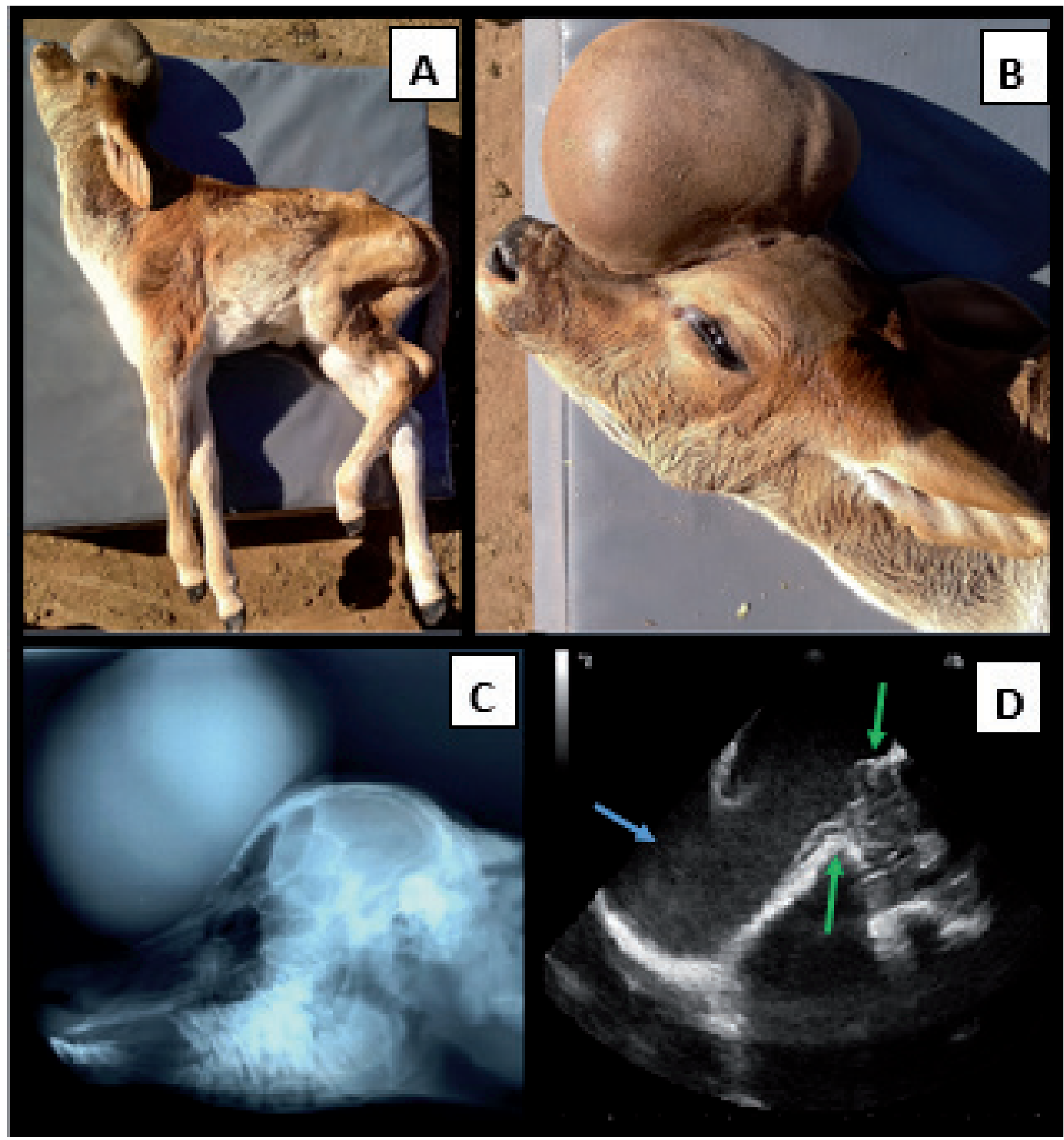

Figure 1. A- A 3-day-old calf presenting with increased volume in the frontal region, neurological symptoms, opisthotonus, and thoracic limb spasticity. B- Increased volume of floating mass extending from supraorbital curvature of the frontal bone to the end of the nasal bones, following the midline. CLatero-lateral radiographic image of the skull showing a mass with radiopacity characteristic of soft tissues, rounded and well-defined contours, located externally and in close contact with the skull in the region of frontal bone. D- Ultrasound image showing a well-defined hypoechogenic content (blue arrow) with loss of bone continuity of the frontal cranial bone and communication with the braincase (green arrows). 


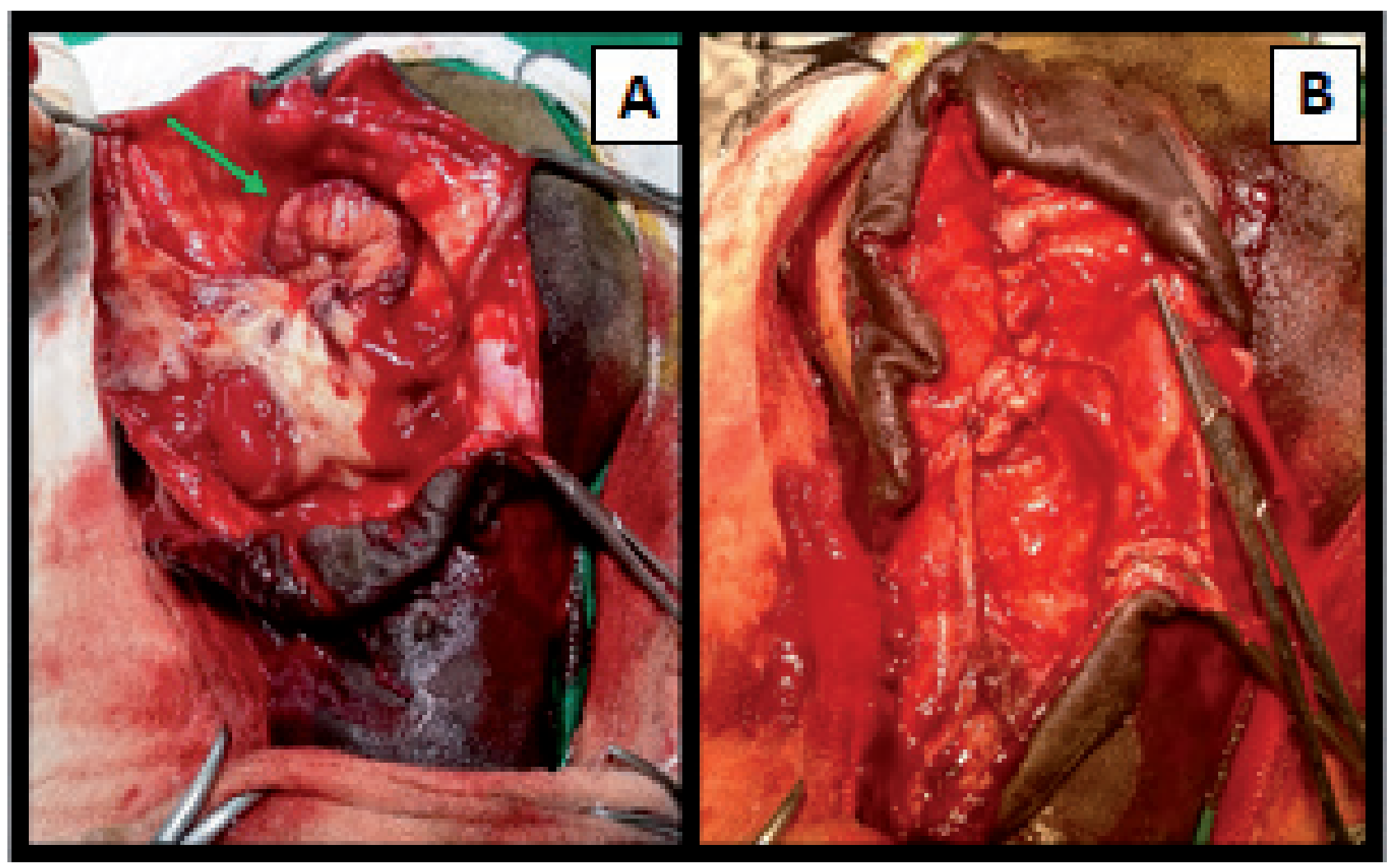

Figure 2. A- Circular failure: $4.5 \mathrm{~cm}$ circular gap in the frontal bone, making it possible to observe part of the right frontal lobe. B- Coaptation of the meningeal edges with Absorbable 0 catgut suture applied in a simple continuous pattern.

improvement, and we opted for performing euthanasia on the third postoperative day. The anatomopathological evaluation of the nervous system showed atrophy of the diencephalon and corpus callosum and absence of third and fourth ventricles.

\section{DISCUSSION}

Meningocele originates from a focal dehiscence in the neural tube of the embryonic ectoderm, and, consequently, a failure in the development of the skeletal shell, named cranioschisis [4]. This, in turn, allows secondary herniation of cranial tissues such as meninges and encephalon, causing meningocele or meningoencephalocele.

The clinical signs of meningocele are generally observed in newborn calves, and the pathology is not reported in aborted animals, which explains the fact that all cases reported in the literature are of calves born at term.

Treatment success is variable. In general, it depends on the absence of neurological symptoms, which are invariably linked to morphological alterations in nervous tissue. Thus, animals with neurological symptoms have poor prognosis and may even die spontaneously $[11,12]$. Some authors report the surgical reduction of a 7-cm cranioschisis in a calf using a homologous graft of ear cartilage [9]. Despite the surgical success and absence of neurological abnormalities before and after the procedure, the animal died nine days after the procedure. Necropsy revealed encephalitis and purulent intracranial content.

Surgical reduction without the use of grafts, as in this report, was successfully performed [8]. The authors reported covering a $7-\mathrm{cm}$ circular gap in the frontal bone thought coaptation of the meningeal edges using a simple continuous pattern of nylon suture, followed by dehorning. In this case, the animal showed no neurological abnormalities and had a good prognosis. Although the animal in the current report clearly did not have a good prognosis for survival, we decided to perform the surgical procedure mainly for scientific and academic interest. As expected, after three days the animal showed no improvements in the initial neurological symptoms; in permanent lateral decubitus position, opisthotonus, spastic paresis in the thoracic limbs and flaccid paresis of the pelvic limbs, presence of tremors and eventual pedal movements, alert attitude, absence of changes in pairs of cranial nerves, and presence of sucking reflex; when euthanasia was indicated. 
Meningocele is a sporadic or epidemiologically congenital alteration related to specific etiological factors. Among the factors reported in the literature are the intake of Mimosa tenuiflora [2,10], Poincianella pyramidalis [1], and genetic abnormalities, such as autosomal recessive genes [12].

The embryological origin of the central nervous system is from the neural plate of the ectoderm. While the neural tube is observable in embryos from the $17^{\text {th }}$ day, complete organogenesis is observed after 110 days [3]. Susceptibility to genetic or external factors varies with the stage of development and decreases with increased fetal age [5]. Thus, it is assumed that the variability in terms of presence or absence of and type of neurological symptoms depend on the etiologic agent and the stage of embryonic development when the embryo was exposed to it.

Some authors reported a case of cranioschisis with meningocele in a Swiss brown calf [12]. The animal had a $17 \times 15 \mathrm{~cm}$ saccular protrusion on the frontal surface of the skull covered by skin and hair, containing $200 \mathrm{~mL}$ of serosanguineous fluid, agenesis of the nasal septum, prognathia, dermoid cyst, and brain hypoplasia with prominent macrogyri. Given the lack of evidence associating this alteration with other etiologies already reported in the literature, we suggest that the presence of autosomal recessive genes, which have not yet described or identified, might be the cause of cranioschisis.

More case studies are needed to elucidate the etiology and pathogenesis of this disorder in bovines, since the cases described in the literature are not associated with the most commonly reported causes, such as the ingestion of certain plants $[1,2,10]$.

We conclude that the surgical treatment of cranioschisis associated with meningocele in bovine species presented in this report had an unfavorable prognosis. As observed in other cases, when the animals have neurological symptoms the prognosis is bleak, probably due to morphological and functional changes of congenital origin in the nervous tissue, as described in the literature.

\section{MANUFACTURERS}

${ }^{1}$ Cristália Produtos Químicos Farmacêuticos Ltda. Itapira, SP, Brazil.

${ }^{3}$ Chemitec Agro-Veterinária Ltda. Ipiranga, SP, Brazil.

${ }^{2}$ Eurofarma Laboratórios S.A. Ribeirão Preto, SP, Brazil

${ }^{4}$ UCBVet Saúde Animal. Ribeirão Preto, SP, Brazil

${ }^{5}$ MSD Saúde Animal. Cruzeiro, SP, Brazil

${ }^{6}$ JP Indústria Faracêutica S.A. Ribeirão Preto, SP, Brazil

Declaration of interest. The authors report no conflicts of interest. The authors alone are responsible for the content and writing of the paper.

\section{REFERENCES}

1 Correia D.A.B., M. Neto G.B., Gomes D.L.S. \& Torres M.B.A. 2017. Congenital malformations and abortions induced experimentally by the ingestion of Poincianella pyramidalis (Tul.) LP Queiroz (catingueira) in sheep. Pesquisa Veterinária Brasileira. 37(12): 1430-1436.

2 Dantas A.F.M, Riet-Correa F., Medeiros G.J.N.G., Pimentel L.A., Anjos B.L. \& Mota R.A. 2010. Malformações congênitas em ruminantes no semiárido do Nordeste Brasileiro. Pesquisa Veterinária Brasileira. 30(10): 807-815.

3 Ferreira A.O., Vasconcelos B.G., Favaron P.O., Santos A.C., Leandro R.M., Pereira F.T.V., Maria D.A. \& Miglino M.A. 2018. Bovine central nervous system development. Pesquisa Veterinária Brasileira. 38(1): 147-153.

4 Grosso F.V., Tinckler S., Lim C.K., Vanderpool A. \& Ramos-Vara J. 2018. Radiographic, ultrasonographic and post-mortem magnetic resonance imaging features of meningoencephalocele in a calf with tibial hemimelia syndrome. Archives on Veterinary Science and Technology. 10(1): 1-4.

5 Jubb K.V.F. \& Huxtable C.R. 1993. Crania Bifida and Related Defects. In: Jubb K.V.F., Kennedy P.C. \& Palmer N. (Eds). Pathology of Domestic Animals. 4th edn. San Diego: Academic Press, pp.273-274.

6 Kwon K., Lee B., Choi S., Cho J., Lee Y. \& Choi H. 2017. Diagnostic imaging of congenital meningoencephalocele in a holstein calf. Journal of Embryo Transfer. 32(1): 33-38.

7 Leipold H.W. \& Dennis S.M. 1987. Congenital defects of the bovine central nervous system. Veterinary Clinics of North America: Food Animal Practice. 3(1): 159-177.

8 Nogueira D.B., Bastos R.M., Rocha L.M.S.B., Rocha E.F., Nóbrega Neto P.I., Miranda Neto E.G. \& Silva T.R. 2017. Correção cirúrgica como tratamento de meningocele associada à craniosquise em bezerro: relato de caso. $M e$ dicina Veterinária (UFRPE). 11(4): 222-226. 
9 Oliveira Filho J.P., Badial P.R., Oliveira A.P., Alvarez L.E.C. \& Costa J.L.O. 2014. Cranioplasty for repair of cranioschisis associated with meningocele in a Jersey calf. Veterinária e Zootecnia. 21(3): 392-398.

10 Santos J.R.S., Dantas A.F.M \& Riet-Correa F. 2012. Malformations, abortion, and embryonic death in sheep caused by the ingestion of Mimosa tenuiflora (Leguminosae). Pesquisa Veterinária Brasileira. 32(11): 1103-1106.

11 Silva L.F., Rabelo R.E., Santos G.P., Aguiar O.L.R., Sonne L., Barros C.S.L. \& Sant'Ana F.J.F. 2016. Multiple congenital encephalic malformations in a calf. Brazilian Journal of. Veterinary Pathology. 9(3): 103-107.

12 Yaman T., Erdoğan S., Terzi F. \& Özyildiz Z. 2013. Congenital meningoencephalocele in a Brown Swiss calf: a case report. Eurasian Journal of Veterinary Science. 29(2): 110-103. 